University of Nebraska - Lincoln

DigitalCommons@University of Nebraska - Lincoln

Faculty Publications from the Harold W. Manter Laboratory of Parasitology

$12-1967$

\title{
Fessisentis necturorum sp. n. (Acanthocephala: Fessisentidae), a Parasite of the Gulf Coast Waterdog, Necturus beyeri
}

\author{
Brent B. Nickol \\ University of Nebraska - Lincoln, bnickol1@unl.edu
}

Follow this and additional works at: https://digitalcommons.unl.edu/parasitologyfacpubs

Part of the Parasitology Commons

Nickol, Brent B., "Fessisentis necturorum sp. n. (Acanthocephala: Fessisentidae), a Parasite of the Gulf Coast Waterdog, Necturus beyeri" (1967). Faculty Publications from the Harold W. Manter Laboratory of Parasitology. 354.

https://digitalcommons.unl.edu/parasitologyfacpubs/354

This Article is brought to you for free and open access by the Parasitology, Harold W. Manter Laboratory of at DigitalCommons@University of Nebraska - Lincoln. It has been accepted for inclusion in Faculty Publications from the Harold W. Manter Laboratory of Parasitology by an authorized administrator of DigitalCommons@University of Nebraska - Lincoln. 


\title{
FESSISENTIS NECTURORUM SP. N. (ACANTHOCEPHALA: FESSISENTIDAE), A PARASITE OF THE GULF COAST WATERDOG, NECTURUS BEYERI
}

\author{
Brent B. Nickol* \\ Department of Zoology and Physiology, Louisiana State University, Baton Rouge
}

ABSTRACT: Specimens of a previously undescribed species of the genus Fessisentis were taken from the Gulf Coast waterdog, Necturus beyeri beyeri, in southeastern Louisiana. This is the third species of the genus to be described and the first published record of Fessisentis from an amphibian. The new species has a shorter body, smaller proboscis hooks, and a proportionately larger proboscis than $F$. fessus. The species from Necturus has more longitudinal rows of proboscis hooks each with fewer hooks, relatively smaller male genitalia, and proportionately longer lemnisci than $F$. vancleavei.

In the fall of 1962 and the spring of 1963, a study was made of the Acanthocephala of the Caudata found in Louisiana. This study was based on the collection of 202 specimens of Caudata representing eleven species. Acanthocephalus acutulus Van Cleave, 1931, was found in one of the 67 Plethodon glutinosus examined. Ten of 11 Necturus beyeri beyeri were found infected with an undescribed species of Fessisentis. The following description is based on a series of 75 mature worms ( 44 females and 31 males).

\section{METHODS}

The salamanders were killed with ether and immediately examined for acanthocephalans. The worms were removed from the hosts and placed in tap water until dead. They were fixed at room temperature in an alcohol-formalin-acetic acid mixture in the proportions recommended by Van Cleave (1953), stained in Mayer's carmalum, dehydrated, cleared in xylene, passed through xylenepermount mixtures and mounted in permount. All measurements are in microns with averages in parentheses unless otherwise stated.

\section{Fessisentis necturorum sp. $n$.}

(Figs. 1-6)

\section{Description}

General: With characteristics of the genus Fessisentis. Body length 4.5 to $12.7 \mathrm{~mm}$ (8.6); greatest width near anterior end 440 to 960 (780). Proboscis with a length of 285 to 365 (320), maximum diameter of 143 to 162 ( 149 ), and armed with 14 to 20 longitudinal rows of 6 to 9 hooks each; largest hooks just anterior to middle of proboscis, smallest hooks at base. Hook roots slightly longer than thorns, unmodified, difficult to distinguish in whole mounts. Basal one or two spines of each row root-

Received for publication 5 April 1967.

* Present address: Department of Zoology and Physiology, University of Nebraska, Lincoln, 68508 . less. Proboscis receptacle 330 to 610 long with ganglion near base. Lemnisci one to two times length of proboscis receptacle, nearly always equal in length and usually not lobed.

Males: Average body length $8 \mathrm{~mm}$. Proboscis armed with 14 to 18 (usually 16 ) longitudinal rows of 6 to 8 hooks each; largest hooks 35 to 44 (37) long; smallest hooks 15 to 24 (18) long. Testicular field at least 10 times as long as wide. Male genitalia always more than $50 \%$ of body length, rarely as much as $75 \%$. Cement glands elongate, claviform, four in number.

Females: Average body length $8.9 \mathrm{~mm}$. Proboscis armed with 14 to 20 (usually 17 or 18 ) longitudinal rows of 6 to 9 hooks each; largest hooks 25 to 44 (39) in length; smallest hooks 16 to $25(20)$ in length. Uterine bell average 166 long by 89 wide. Female genitalia, genital pore to anterior edge of uterine bell, always less than $15 \%$ of body length and usually less than $10 \%$. Eggs removed from body cavity of fixed female average 66.5 by 9.5 .

Type host: Necturus beyeri beyeri.

Type locality: Bogue Falaya River near Folsum, Louisiana.

\section{Remarks}

Fessisentis fessus Van Cleave, 1931, and F. vancleavei Haley and Bullock, 1953, are the only two previously described species of the genus Fessisentis. F. necturorum differs from $F$. fessus in its shorter body, proportionately larger proboscis, smaller proboscis hooks, relatively shorter lemnisci (which never reach the margin of the anterior testis), and shorter eggs.

Fessisentis necturorum more closely resembles $F$. vancleavei than it does $F$. fessus. $F$. vancleave $i$ is described as having 12 longitudinal rows of proboscis hooks of eight or nine hooks per row, basal proboscis hooks of 22 to $33 \mu$ in length, genitalia that occupy about three-fourths of the body cavity, lemnisci nearly equal to the proboscis receptacle in length, and a proboscis 355 to $365 \mu$ long (Haley and Bul- 

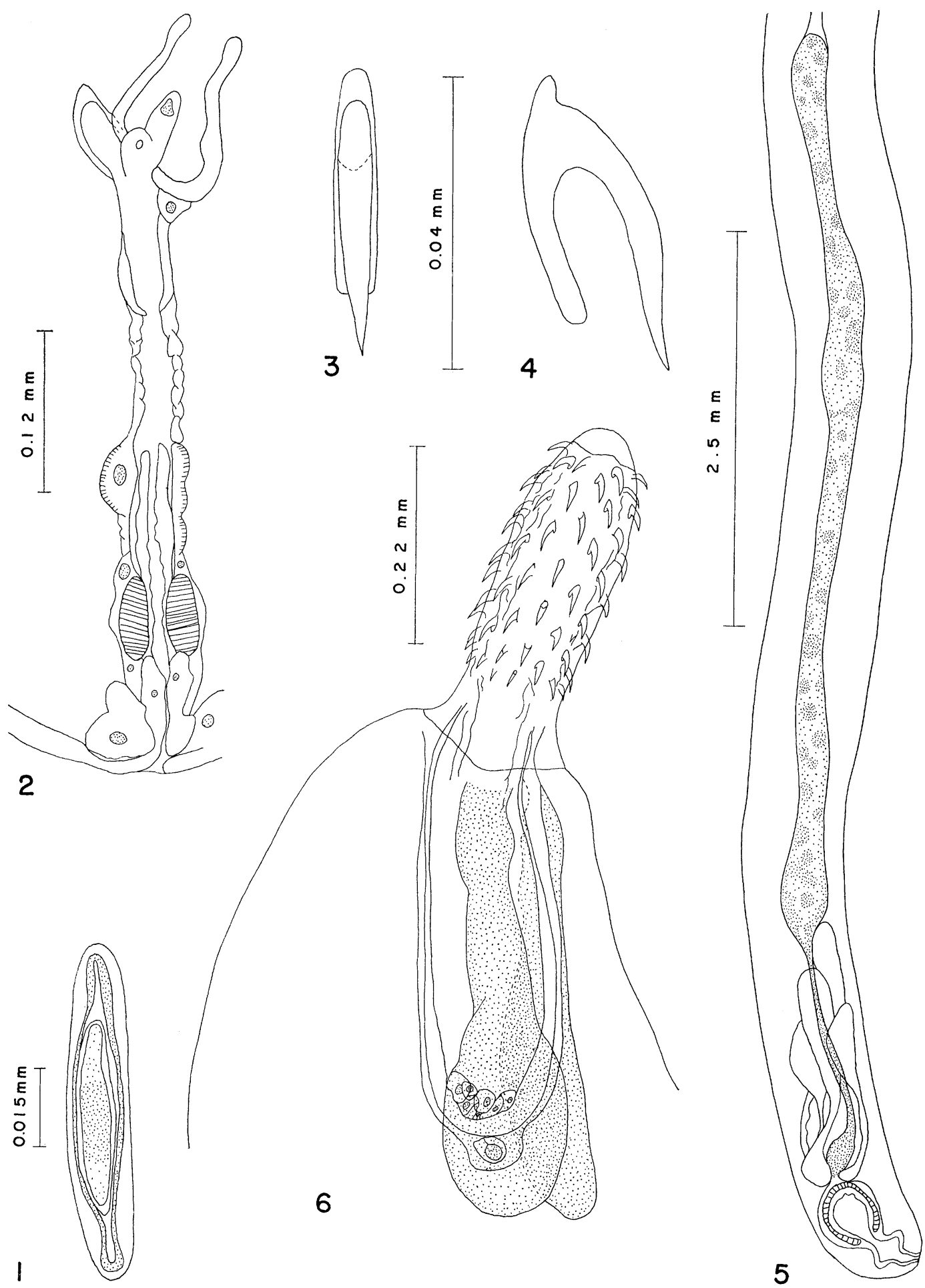

6
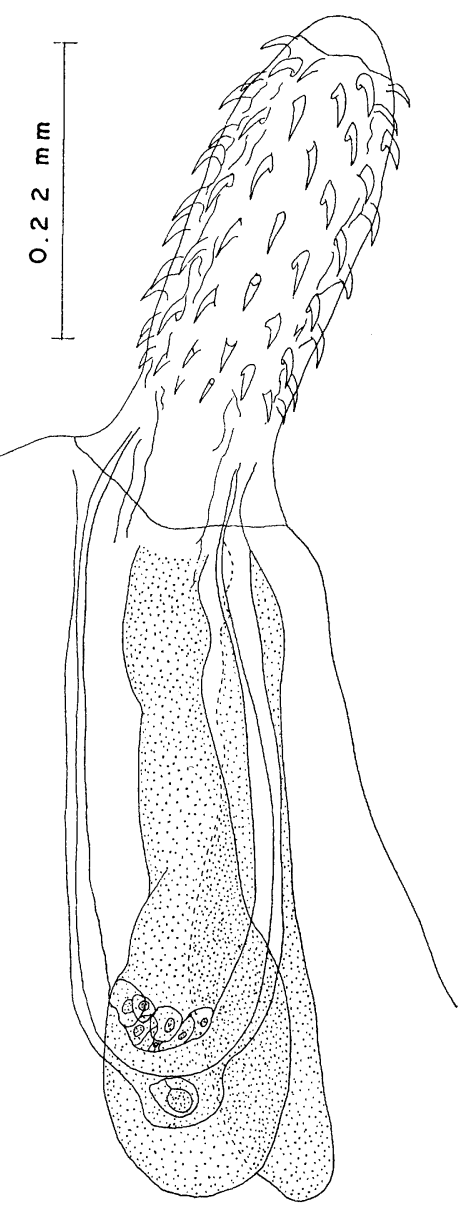

5

Figures 1-6. Camera lucida drawings of Fessisentis necturorum sp. n. 1. Egg removed from body cavity of female. 2. Genital apparatus of female as seen through body wall. 3. Frontal view of hook from near proboscis apex. 4. Lateral view of hook from midlevel of proboscis. 5. Posterior end of male. 6. Anterior end of male. 
lock, 1953). F. necturorum has more longitudinal rows of hooks, fewer hooks per row, smaller basal hooks, relatively smaller male genitalia, lemnisci which are longer in proportion to the proboscis receptacle, and a smaller proboscis in proportion to the body.

\section{DISCUSSION}

Dr. Wilbur L. Bullock was kind enough to allow examination of specimens identified by him as Fessisentis vancleavei. Several of his specimens have more than the reported 12 longitudinal rows of proboscis hooks and more than nine hooks per longitudinal row. Even though the number of longitudinal rows of these few specimens fell into the range given for $F$. necturorum, the number or hooks per row was always greater than the six to nine of $F$. necturorum. The lemnisci of his specimens were as stated in the original description and never as long in relation to the proboscis receptacle as those of $F$. necturorum.

West (1964) stated that detailed examinations of acanthocephalan eggs have invariably led to a description of four enclosing membranes and that he believes this to be the standard number. Even though but three such membranes were observed in Fessisentis necturorum, four may be present. The "fibrillar coat" was not observed. This membrane, according to West, leads to much of the discrepancy in citing the number of membranes. He further stated that the fibrillar coat is extremely difficult to observe in fixed specimens. As only fixed eggs were available for study, it is felt that this membrane is likely present, but undetectable in the specimens examined.

Fessisentis necturorum is the first member of this genus reported from amphibians. While in several respects, such as body length, relative length of the lemnisci, proboscis length, and proboscis hook lengths, they are intermediate between the two previously known species, the specimens from Necturus form a distinct group and are considered to represent a third species of Fessisentis.

\section{ACKNOWLEDGMENTS}

The author is indebted to Drs. Harry J. Bennett and Kenneth C. Corkum of Louisiana State University and Dr. Wilbur L. Bullock of the University of New Hampshire for their suggestions during the preparation of this paper.

\section{LITERATURE CITED}

Haley, A. J., and W. L. Bullock. 1953. A new species of Acanthocephala from the sunfish, Lepomis gibbosus (Linnaeus), with a redescription of the family Fessisentidae Van Cleave, 1931. Am. Midl. Nat. 50: 202-205.

Van Cleave, H. J. 1931. New Acanthocephala from fishes of Mississippi and a taxonomic reconsideration of forms with unusual numbers of cement glands. Tr. Am. Micr. Soc. 50: 348-363.

- 1953. Acanthocephala of North American mammals. Ill. Biol. Monogr. 23 (1-2): $179 \mathrm{p}$.

West, A. J. 1964. The acanthor membranes of two species of Acanthocephala. J. Parasit. 50: 731-734. 